\title{
System Dynamics in the Combination of Conventional and Traditional Chinese Medicine in the Dynamics of Contagion, Treatment and Cure in the SARS Covid-19
}

\author{
Jorge Luiz Guedes Sant'ana \\ Postgraduate program of Knowledge Management \\ Engineering - Federal University of Santa Catarina \\ Florianópolis SC - Brasil
}

\author{
Tarcisio Vanzin \\ Postgraduate program of Knowledge Management \\ Engineering - Federal University of Santa Catarina \\ Florianópolis SC - Brasil
}

\begin{abstract}
In recent history, humanity is experiencing a confrontation with an invisible enemy, the Covid-19 virus. Even with all the technological resources available, man found himself powerless and thousands of lives have already been lost. It turns out that different ways of coping with the pandemic have obtained different results in terms of effectiveness in reducing the number of deaths. In this sense, the objective of this article is to represent the dynamics of coping with the SARS Covid-19 pandemic with the simulation of scenarios that used Conventional Medicine combined or not with Traditional Chinese Medicine (TCM). The method employed was a mathematical simulation model of system dynamics developed based on 12 randomized controlled clinical studies. The model was used to test four policies to mitigate the effects of Covid-19: i) adequate treatment conditions combining the two techniques; ii) reductions in the administration fee and time of using the TCM; iii) total withdrawal of treatment with TCM and iv) no treatment. The results demonstrates the main actions in the fight against Covid-19, with the invasion of the virus, the compromise of the patient, the defenses and behavior of the organism and the treatment actions only with conventional medicine or combined with traditional Chinese medicine. Thus, the model allows reflecting on how and when to use the available resources, in addition to exploring a new tool in terms of Western science, respecting the very limits that the model provides. Furthermore, this model provides health professionals and scientists with a tool that allows them to dynamically monitor real-time scenarios and simulate future situations regarding decision-making in events that need to be analyzed immediately, such as pandemic and epidemic situations.
\end{abstract}

Keywords:- SARS Covid-19, Traditional Chinese medicine, Systems dynamics, Chloroquine

\section{INTRODUCTION}

In December 2019, a new virus, called SARS-CoV-2, caused an international outbreak of respiratory disease called Covid-19 and researchers evaluate the comparative effects of some drugs and try to find a vaccine [1]. In a broader context, Traditional Chinese Medicine [2] sees this virus as a complex dynamic system and focuses on treatment seeking human balance both internally and in its external environment.

The main current conventional medical strategies [3] administered to patients diagnosed with COVID-19 includes the use of antiviral drugs, antibiotics and, in some severe cases, oxygen therapy and renal therapy.

Chinese medicine management departments and medical institutions in various provinces and cities in China brought together experts in Chinese medicine to participate in large-scale treatment. They proved that the two medicines have their own advantages in the treatment of new infectious diseases by coronavirus, and that Chinese medicine is more recommended for the prevention of the disease and the treatment of mild types. [4].

Due to the efficiency presented by the combination of conventional and traditional Chinese medicine reported by the Chinese, it is necessary for the scientific community and public health managers to review paradigms and evaluate the effectiveness of treatment techniques used by Orientals.

Little is known about what the most efficient strategies are and how to effectively overcome this pandemic. In this way, Systems Dynamics seeks to apply a methodology derived from systemic thinking, which focuses on the analysis of problems in which technical, human and organizational components interact, through computer simulation, known as systems dynamics [5]. 
The dynamics of systems can help in the explicit representation of the interrelation between the factors that promote the improvement of immunity, its effects on the level of impairment by Covid-19 and point the direction for the best to treatment strategies to reduce complications and avoid the death of the patient.

Therefore, the objective of this article is present a model that represents the contagion, treatment and cure dynamics of Covid-19, thus, improving the relationship between conventional and traditional Chinese medicine.

The choice of this theme was due to the ongoing pandemic of Covid-19 and the need to understand the different scenarios encountered in its confrontation. Problems of uncertainties in the use of medications such as chloroquine [6], which causes adverse effects on the functioning of the cardio-circulatory system, the lack of a vaccine and the way China, Korea and other Asian countries managed to control the pandemic using the combined treatment of the two medicines. Thus, the main contribution of this article is to provide a better understanding of the effectiveness of therapeutic strategies aimed at preventing, treating and curing Covid-19.

\section{METHOD}

The simulation model was developed following the methodological procedure of systems dynamics [5]. This technique has been widely used to simulate problems in the areas of business, environmental management and energy planning, among others, and more recently, in several health problems [7, 8]. Mathematically, a system dynamics model can be represented by equations of the type [5]:

(Times New Roman)

$\frac{d}{d t} X=f(X, p)$

\section{Being:}

$\mathrm{X}=$ vetor de ' $\mathrm{n}$ ' estoques; $\mathrm{dX} / \mathrm{dt}=$ taxa líquida de mudança do vetor $\mathrm{X} ; \mathrm{f}=$ função $\mathrm{n}$-dimensional e usualmente nãolinear; e $\mathrm{p}=$ vetor de parâmetros.

For the theoretical foundation of this model, a literature search was carried out from April 25 to May 10,
2020, in the databases of Ebscos; Science Direct, Web of Science, Bireme, Pubmed, Wile, China National Knowledge Infrastructure (CNKI) e Chinese Science and Technology Periodical Database (VIP). The strategies and results of 12 randomized, controlled clinical studies on the treatment of patients diagnosed with Covid-19 were observed and analyzed, in which 6 (six) studies reported treatment with conventional medicine and 6 (six) treatment combined with traditional Chinese medicine. All studies were carried out from February to May 2020, the period with the highest incidence in China, Europe, the United Kingdom and the USA, as shown in Table 1.

From the observation of studies only with conventional medicine or combined with traditional Chinese medicine, it was possible to verify the effectiveness of treatments and conclude which is the best strategy. Of the patients diagnosed with Covid-19, 240 were treated with conventional medicine and 232 with conventional medicine combined with traditional Chinese medicine, totaling 472 cases. Among the 12 literatures, 5 were published in English and 7 in Chinese.

To develop the model, some aspects of the research were highlighted: i) potential of Covid-19, ii) contaminated patient, iii) desired immunity, iv) preserved organic functions, v) effect of traditional Chinese medicine, vi) potential of Medicine conventional and others.

Finally, after several critical discussions, a final model structure was generated and inserted in the software Stella Architect (www.iseesystems.com). The next step was the parameterization of the model. For this, data were estimated based on the treatment strategies adopted in the 12 studies and in them the model was adjusted to represent the base scenario. The behavior of the scenario constructed as a base was estimated according to what happened with the pandemic in the period from February to May 2020, and the model's ability to synthetically reproduce the behavior observed in the studies was verified. Thus, the model was simulated to test four policies to mitigate the effects of Covid-19: i) adequate treatment conditions combining the two techniques; ii) reductions in the administration fee and time of using the TCM; iii) total withdrawal of treatment with TCM and iv) no treatment. 
Table 1: Times New Roman

\begin{tabular}{|c|c|c|c|}
\hline \multirow{2}{*}{ Study } & \multicolumn{3}{|c|}{ Design } \\
\hline & Population & Intervention & Results \\
\hline \multicolumn{4}{|c|}{ CONVENTIONAL MEDICINE } \\
\hline $\begin{array}{l}\text { Gautret P. [9] et al } \\
2020\end{array}$ & 36 & $\begin{array}{l}\text { Hidroxicloroquina }+ \\
\text { Azitromicina }\end{array}$ & Improvement of Covid-19 pneumonia \\
\hline Cai Q [10] et al;. 2020 & 80 & $\begin{array}{l}\text { Favipiravir }+ \\
\text { Lopinavir }\end{array}$ & Improvement of Covid-19 pneumonia \\
\hline $\begin{array}{l}\text { Borba M [11] et al; } \\
2020\end{array}$ & 81 & Cloroquina difosfato & Improvement with low dosage \\
\hline Chen, J [12] et al; 2020 & 30 & Hidroxicloroquina & $\begin{array}{l}\text { Radiological progression in the control } \\
\text { group }\end{array}$ \\
\hline $\begin{array}{l}\text { Cao B [13] et al; } \\
\text { (2020) }\end{array}$ & 199 & Lopinavir + ritonavir & Clinical improvement \\
\hline $\begin{array}{l}\text { Chen Z [14] et al., } \\
2020\end{array}$ & 62 & Hidroxicloroquina & Melhora da pneumonia da Covid-19 \\
\hline \multicolumn{4}{|c|}{ TRADITIONAL CHINESE MEDICINE } \\
\hline Qian Y [15] 2020 & 103 & Trad Chin Med + Conv Med & Improvement of Covid-19 pneumonia \\
\hline Ruibing W [16] 2020 & 101 & Trad Chin Med & $\begin{array}{c}\text { Clinical improvement (Shortness of } \\
\text { breath) }\end{array}$ \\
\hline $\begin{array}{l}\text { Hui Min S[17] et al; } \\
\qquad 2020\end{array}$ & 60 & Trad Chin Med + Conv Med & Clinical improvement \\
\hline $\begin{array}{l}\text { Wenguang X[18] et al; } \\
2020\end{array}$ & 57 & Trad Chin Med + Conv Med & Clinical improvement \\
\hline $\begin{array}{l}\text { Cong yu Z [19] et al; } \\
2020\end{array}$ & 52 & Trad Chin Med + Conv Med & Clinical improvement \\
\hline $\begin{array}{l}\text { Hui Min S [20] et al; } \\
\qquad 2020\end{array}$ & 44 & Trad Chin Med + Conv Med & Clinical improvement \\
\hline
\end{tabular}

Table 1:- Results of 12 randomized, controlled clinical studies on the treatment of patients diagnosed with Covid-19. $\mathrm{P}$ value $(\mathrm{p}<0,05)$.

\section{RESULTS}

The model represented in Figure 1 demonstrates the structure to combat Covid-19, with the presence of the virus, the patient's compromise, the organism's defenses and behavior, the treatment actions only with conventional medicine or combined with traditional Chinese medicine.

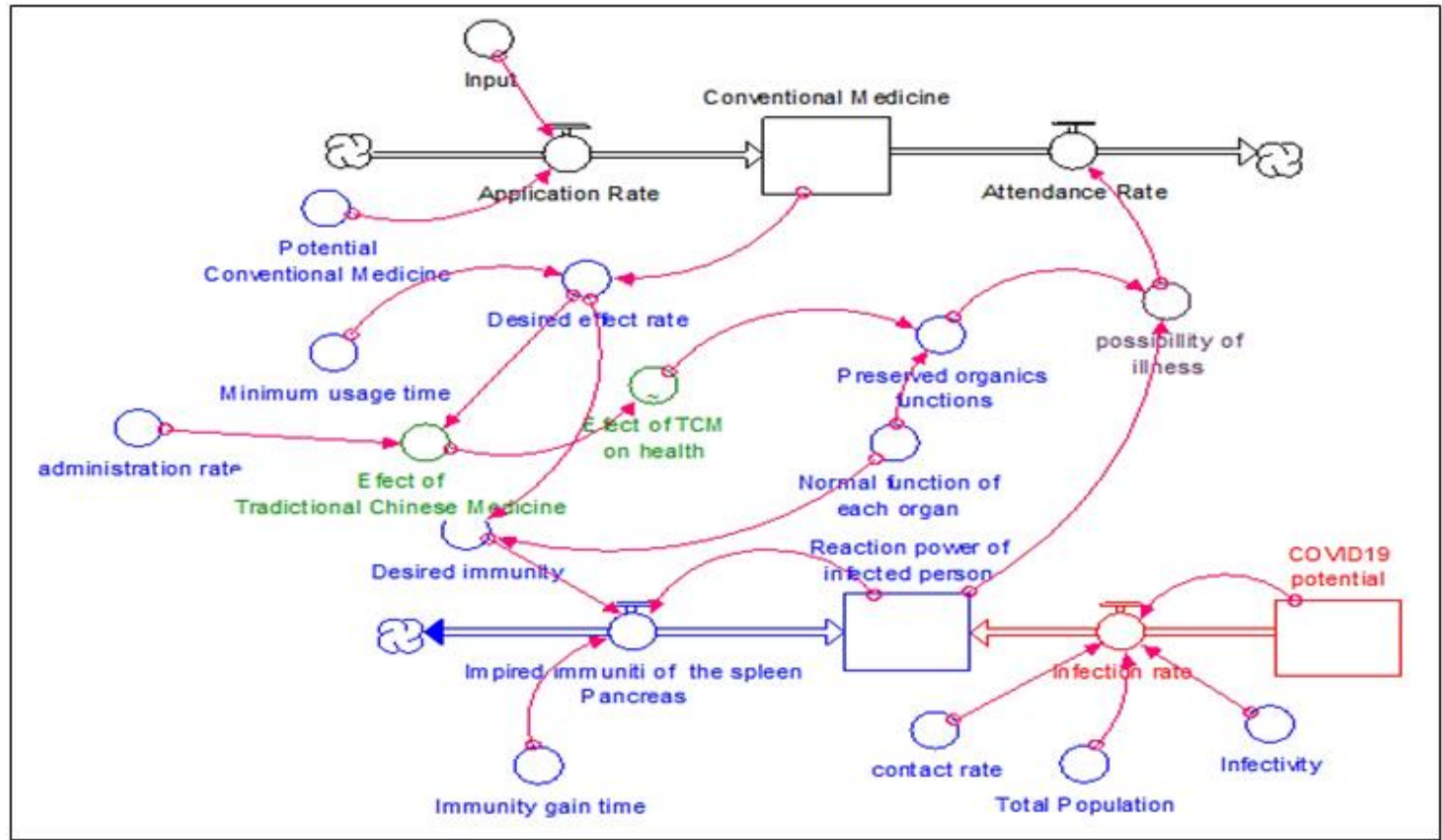

Fig 1:- System Dynamics Model for the combined treatment of Covid-19 
Next, the mathematical equations are formulated to below, will have effects on health, on the possibility of recovery, on the contaminated patient, on the desired immunity and on the infection rate. It is noteworthy that the formulated equations (presented below) are the product of simple algebraic operations such as sum, subtraction, division and product available in the construction of the model. In other words, equations 1 to 6 were deduced by the authors to explain the phenomena observed in them.

$\theta_{t}^{e}=\alpha_{t}^{e} X \beta_{t}^{\theta}$

Thus, the Possibilities of recovery $\rho_{t}$ is the multiplication between the infected patient in the period $\mathrm{t}$, $\Psi_{t}^{e}$ and organic functions preserved in the same period $\theta_{t}^{e}$, represented in the language of systems dynamics by the following equation:

$\frac{d}{d t} \rho_{t}=\Psi_{t}^{e} X \theta_{t}^{e}$

The Contaminated Patient $\Psi_{t}^{e}$ is defined by the signs and symptoms that are present in relation to the action of the Covid-19 virus.

The organic functions preserved in the $\theta_{t}^{e}$, correspond to the general effect on patient health $\alpha_{t}^{e}$, multiplied by the normal functioning of each organ $\beta_{t}^{e}$ according to the following equation:

$$
\theta_{t}^{e}=\alpha_{t}^{e} X \beta_{t}^{e}
$$

Thus, as it improves the overall health effect $\alpha_{t}^{e}$ and the normal functioning of each organ $\beta_{t}^{e}$, the better the organic functions will be preserved $\theta_{t}^{e}$. The desired Immunity $\gamma_{t}$ will depend on the relationship of the desired effect of conventional medicine $\epsilon_{t}^{a}$ multiplied by the normal functioning of each organ per day $\phi_{t}^{a}$ as seen in the formula:

$$
\gamma_{+}=\epsilon_{\mathrm{t}}^{a} X \phi_{\mathrm{t}}^{a}
$$

The infection rate $\sigma_{t}$ will depend on other factors: the Potential of Covid-19 $\varsigma_{t}^{e}$, divided by the total population $\tau_{t}^{e}$, multiplied by infectivity $\pi_{t}^{e}$ that multiplies by social distance $\omega_{t}^{e}$ :

$$
\frac{d}{d t} \sigma_{t}=\omega_{t}^{e} X \pi_{t}^{e}\left(\zeta_{t}^{e} \div \tau_{t}^{e}\right)
$$

The infection rate $\sigma_{t}$ corresponds to the degree of contagion of the virus and the potential of Covid-19 $s_{t}^{e}$ to spread in relation to the size of the total population $\tau_{t}^{e}$. The power of infectivity $\pi_{t}^{e}$ is related to the way in which the social distance is increased or reduced $\omega_{t}^{e}$. In summary, Figure 1 demonstrates that when contagion occurs, patient treatment strategies with the combination of conventional and traditional Chinese medicine work properly and the system remains in balance.
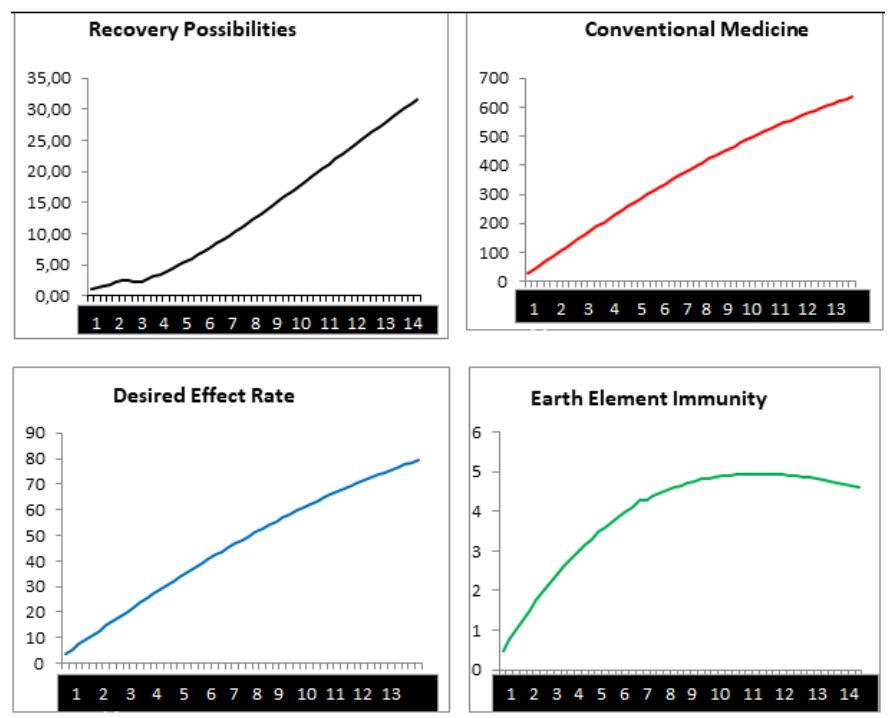

Fig 2:- Scenarios of excellence in treatment reproducing the patient's helath behavior

Figure 2 shows the result of the treatment excellence scenario over the course of 14 days (period in which the virus may have greater action according to World Health Organization). A balance is estimated in the interventions of both Conventional Medicine and Traditional Chinese Medicine. It is noted that, under these conditions, the chances of recovery are growing; the action of conventional medicine tends to balance the clinical condition. That is, it represents the fight against the virus in the beginning with a tendency to balance the patient's health. Thus, the desired rate of effect increasing in the beginning tends to balance and Immunity in the earth element that grows more vigorously in the beginning and tends to decline in the last days of treatment.

After explaining the model and presenting the scenario of excellence, some scenarios were simulated in order to verify the impact on the possibilities of recovery, the desired effect rate and the patient's immunity respectively. The first scenario establishes the maintenance of conventional medicine dosages and a reduction in administration fees for traditional Chinese medicine. In this way, the effect of reducing the attendance of Traditional Chinese Medicine (TCM) is simulated, considering that the total attendance and medication is around $100 \%$ of the necessary for the scenario presented above. The simulated reductions are $70 \%$ of the administration fee and $60 \%$ of the time of using the TCM, Graphic 1 shows the results. 


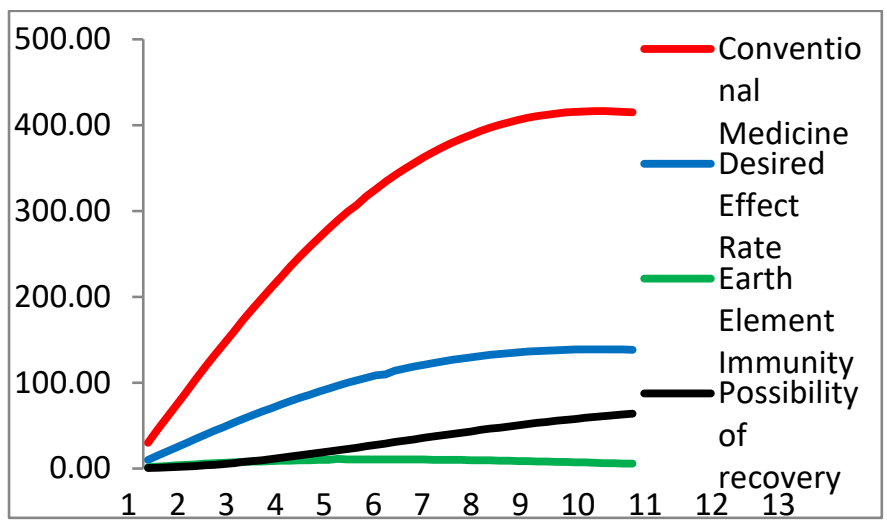

Graph 1:- Scenarios of reductions in the administration fee and TCM usage time

According to the results, Graphic 1 shows that, as the treatment progresses, with the significant reduction in the use of TCM, there is a drastic reduction in the patient's immunity and the possibility of its recovery, there is also maintenance of the effects of conventional medicine that tends to reduce its effect from the 14th day. This collapse behavior of the treatment scenario is more evident when the use of TCM is completely eliminated. The model shows that only the use of conventional medicine reduces the confrontation power of Covid-19.

The next scenario seeks to present the impact of the total withdrawal of treatment with Traditional Chinese Medicine (TCM), considering, again, this withdrawal at $100 \%$. Graphic 2 presents the results of the second set of scenarios.

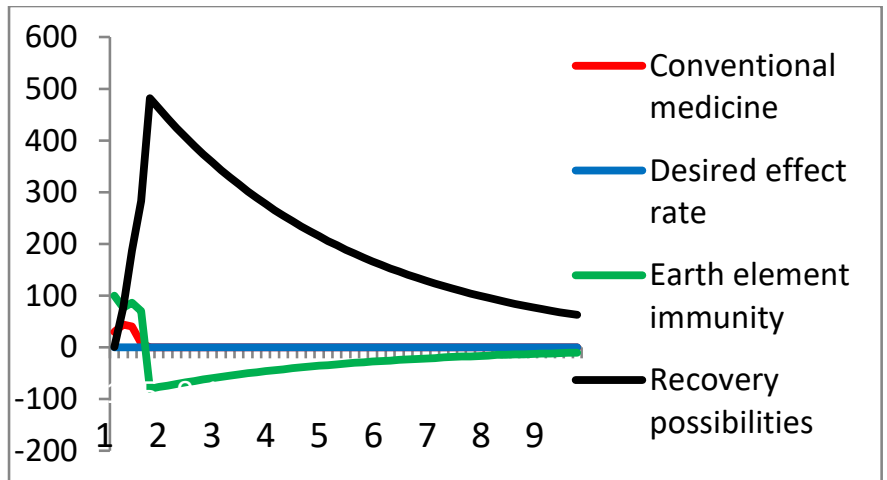

Graph 2:- Scenarios of the policy for withdrawing treatment with TCM

With a policy with exclusive treatment with conventional medicine, it is possible to verify the lack of therapeutic response. Thus, the possibility of patient recovery is reduced to worrying levels. Following this trend, the effect of the therapy is 0 (zero) and the immunity of Pancreas Spleen of the earth element reaches negative rates. Thus, according to Graphic 2, with the exclusion of treatment with TCM, the possibility of effectiveness of conventional medicine is limited.

According to the model, when combined [3, 4, 16, 17, 18, 19] Conventional and Traditional Chinese Medicine makes treatment more effective, but by excluding any of these techniques this efficacy ceases to exist. According to the results presented in the articles, the combination of Western medicine ${ }^{3}$ with TCM in some oriental countries such as China and South Korea is a sign of this effectiveness.

The scenario simulations have limitations, they were not followed up at the locations, they will depend on the level of contagion, the availability of the health service, the availability of medicines, the patient's response to the signs and symptoms that he will be presenting and will also depend on the evolution each case. To the extent that the health professional manages these symptoms, the better the response to their care and the better the patient will be.

\section{DISCUSSION}

When building a System Dynamics model, the researchers sought to represent the dynamics of the treatment of patients diagnosed with Covid-19, to monitor problem points in the care structure of these patients using computer simulations, using an easily understood representation. One of the main values of systems models is that they show how a set of changes that affects many aspects of a complex structure [21].

This model consisted of multiple feedback loops containing a diverse range of components, including impairment of the patient's health, the rate of infection, the effect of Traditional Chinese Medicine on treatment, the dosage of conventional medicine, the desired immunity and others.

The model makes it possible to understand the dynamics of operation of the two forms of treatment and, in addition, it is possible to predict trends for future situations under various scenarios [22], as are the case of sequels situations in which an aggravation of these conditions is possible and the possibility of resurgence of new events of this nature. The demands presented in the model depict hypothetical cases of patients infected with the Covid-19 virus and the information was based on the research findings already mentioned in Table 1 .

The current Covid-19 framework does not offer a specific vaccine or antiviral regimen used to treat critically ill patients. Patient management focuses primarily on providing [23] supportive care, for example, oxygenation, ventilation and fluid management. The combined treatment of systematic low-dose and antiviral corticosteroids and inhalation by interferon atomization was encouraged as part of the critical management of COVID-19.

The main drugs [27] researched by World Health Organization in the treatment of Western medicine are Chloroquine and Hydroxychloroquine associated with the antibiotic Azithromycin, Tocilizumab and Remdesivir. There is also, the combination of HIV drugs, formed by Lopinavir and Ritonavir; the combination of Lopinavir and Ritonavir together with the substance Interferon beta-1b, 
used to treat multiple sclerosis; and Antiviral Remdesivir, developed for Ebola cases.

The way in which Easterners [24] use formulas with herbs, soups and acupuncture in order to increase immunity, eliminate secretions and improve patient resistance may have been a differential in preventing and coping with Covid-19. Modern pharmacological studies [26] have shown that the combined use of herbs with conventional medicine has potential effects of antiinflammatory and antipyretic, antiviral, antioxidant, regulating immunity and protecting viscera and tissues in the treatment of COVID-19.

The use of herbs combined [17] with western medicine in the treatment of COVID-19 is more effective than the isolated treatment of western medicine, which can significantly reduce the patient's hospitalization time, the time of improvement of clinical symptoms and the time of improved lung function. Based on routine treatments, the use of this technique significantly improved the cough and sputum symptoms of patients with COVID-19, reduced duration of cough and sputum symptoms, pathological lung damage, improved respiratory function and improved symptoms of fever, fatigue, dry pharynx and sore throat [18].

When combined with drugs from Western pharmacology, Chinese phytotherapy [27] widely used in China has the potential to regulate mainly the immune system, having significant effects, highlighting the antiviral effect of traditional Chinese medicine. Several of results [28] from pharmacological, pharmacodynamics and clinical research have confirmed that, medicinal plants have significant antiviral effects and are effective for respiratory diseases such as viral pneumonia and upper respiratory tract infection.

The way in which the dynamics of complex systems allows us to analyze complex situations with their concepts, principles and methods, could cause an important change in how the West observes Chinese medicine. Allow us to reflect on how to also use the natural resources valued by Chinese medicine and, in an intelligible way in terms of Western science, respect our own commitments.

Thus, the Orientals highlight ways in which the Western orthodox medical worldview contrasts with that of Chinese medicine, and thus the ways in which complex systems approximate Western medicine [29] itself and also differ from orthodoxy. The Oriental perspective provides an articulation of Chinese medical goals and practices that emanate from their conceptions of health and illness, allowing for involvement with those of Western medicine and highlight the differences between two different approaches to medical treatment and treatment validation.

Oriental medicine associates the disease with natural phenomena that are related to both organic and natural phenomena. The first group [25] of Chinese medicine experts who arrived in Wuhan believed that new coronavirus pneumonia would have moisture as its main characteristic. As diarrhea is one of the important symptoms of moisture sickness, this correlation was attributed and thus, it is up to the traditional Chinese doctor to promote the balance of the Earth element, since it is there that the climatic factor humidity is manifested.

The model, with its dynamics, proposes a reflection on how to improve the understanding of traditional Chinese medicine on how to interpret the approaches of different pathologies. The Western doctor, when adopting the Cartesian view of seeing believes, is still unable to understand how the oriental interprets the phenomena that occur behind the disease and this knowledge can be valuable for diagnosis and treatment.

In addition, the treatment carried out in China showed the world how efficient the way in which Eastern cultures dealt with "sui generis" phenomena such as SARS Covid19. In a long-term perspective, it is interesting to explore issues related to ways of coping with other ills such as depression, stress, anxiety, heart disease, diabetes and other treaties for millennia with important results.

The adoption of a model with more elements and greater relations increases the validation significantly and may facilitate a closer approximation of the two medicines. The scientific literature on addressing this need is still timid and does not always agree on how and to what extent these variables influence each other and longitudinal empirical studies are still lacking. Despite the mentioned barriers there is a signal that the development of computer simulation tools offers considerable potential for the management of health services.

In particular, the results of this and future studies on the topic may contribute to health science in the sense of designing reform initiatives related to improving the diagnosis and treatment of Covid-19 and several other pathologies, to promoting health with increased immunity, control of stress and anxiety and to decrease its negative consequences in terms of quality of life.

\section{CONCLUSION}

This model of system dynamics allows representing the complex feedback mechanisms involving the procedures adopted by Western and Eastern doctors, physiotherapists and nurses in the fight against SARS Covid-19 in the period from February to May 2020.

In this way, the model allows managers, health professionals and scientists to be able to dynamically follow current scenarios and simulate future situations on the effects of events that need immediate confrontation such as epidemics or pandemics. It also makes it possible to take control measures such as social distance, the distribution of Personal Protective Equipment for essential service professionals, changes in work routines such as the home office and possible forms of intervention through decisions in various health actions. 
In view of the complexity of the health service, despite the limitations, this research hopes to provide a tool capable of assisting managers in coping with complex conditions such as that observed in the pandemic SARS Covid-19, and finally, suggesting that additional research be encouraged, applying the systems dynamics methodology.

\section{REFERENCES}

[1]. O. Farmanli, M. Uysal, E.I Ayhan, C. Gokdemir, O. F. Donmez, S. Bastug, M. Parlak, I. Uckun, A. Jafarov, I. Pamuk, K. Farmanli, I. Karatas, Hypothesis: Advanced Biotechnological Treatment Approaches Against Sars-COV-2 (COVID-19); International Journal of Innovative Science and Research Technology. Vol 5, Issue 4, 217-221,April 2020. DOI: 10.38124/IJISRT20APR398

[2]. Yan Ma. Kehua Zhou, Jing Fan, Shuchen Sun. Traditional Chinese medicine: potential approaches from modern dynamical complexity theories; Frontiers of Medicine; 10, pages28-32(2016).

[3]. Y Yuxin, I Woo S, X Yoong P, M Yang, L Jianchen, Y Chong, Z Haitao, Edward L, W Tao, H Cheng P, The First 75 Days of Novel Coronavirus (SARS-CoV2) Outbreak: Recent Advances, Prevention, and Treatment. Int. J. Environ. Res. Public Health 2020, 17,2323

[4]. Y. Zhang, Y. Meng, Combining Chinese and Western Fighting against New Coronary Pneumonia. Trans. Zhejiang Journal of Integrated Traditional and Western Medicine. China. 2020, 30 (3). 浙江中西医 结合杂志 2020 年第 30 卷第 3 期 Zhejiang JITCWM Vol.30 No.3 2020.Available from: http://subject.med.wanfangdata.com.cn/UpLoad/Files/ 202003/93dff2b58d2c4d4fb32379210d2d090e.pdf

[5]. G. Navid, X Ran, Late retirement, early careers, and the aging of U.S. science and engineering professors. PLoS ONE. 2018;13(12):e0208411. doi: https://doi.org/10.1371/journal.pone.0208411

[6]. S. Yishay. L. Yael, A.S. Bander, B. Hila, S.O. Howard, V Sami, Chloroquine induced torsade de pointes in a COVID-19 patient. Heart Rhythm (2020), May 5. 01-04. doi: https://doi.org/10.1016/ j.hrthm.2020.04.046.

[7]. J. Arif, K. Laura, K. Alicia, Conceptualizing the dynamics of workplace stress: a systems-based study of nursing aides. BMC Health Serv Res. 2017;17(1):12.1-11.

doi: http://dx.doi.org/10.1186/s12913-016-1955-8

[8]. M.A Jo-An, W. Robert, P. Andrew, D. Amanda, H. Mary, W. Andrew. Applications of system dynamics modelling to support health policy. Public Health Res Pract. 2015;25(3):e2531531. doi: http:// dx.doi.org/10.17061/phrp2531531

[9]. G. Philippe, C.L. Jean, P. Philippe. T.H. Van, M. Line, M, Morgaine, D. Barbara, C. Johan, J. G. Valérie,V.E.Vera, VE. T.D. Hervé, H. Stéphane, S.C. Philippe, P. C. Eric. Scola, L.R. Bernard, M.R. Rolain, B. Philippe, P. R. Didier, Hydroxychloroquine and azithromycin as a treatment of COVID-19: results of an open label non-randomized clinical trial. International Journal of Antimicrobial Agents. 2020, 18(5):01-25. https://doi.org/10.1016/j.ijantimicag.2020.105949

[10]. C. Qingxian, Y. Minghui. L. Dongjing, J. Chen, S. Dan, X. Junxia, L. Xuejiao, G. Yauanbo, C. Qiue, Y. Yang, S. Chenguang, L. Xiaohe, P. Ling, H. Deliang, Z. Jing, Z. Shurong, W. Fuxiang, L. Jiaye, C. Li, C. Shuyan, W. Zhaoqin, Z. Zheng, C. Ruiyauan, Z. Wu, L. Yingxia, L. Lei, Experimental Treatment with Favipiravir for COVID-19: An Open-Label Control Study, Engineering, 2020; 11(5):01-07. https://doi.org/10.1016/j.eng.2020.03.007

[11]. G.S.B. Mayla, F.F.V. Fernando, Sampaio, S.S. Vanderson, Alexandre, A.A.A. Marcia, C.M. Gisely, B. Marelo, MS. P.G.M. Mourão, D.B.S. José, B.S. Djane, V.F.G Marcus, A.H. Ludhimila, C.P. Rosemary, A.S.B Antonio, G,F.P. Antonio, D.O.S. James, G.N. Felipe, S.X. Mariana, M.S. André, S. Alexandre, C. Julio, L.N. Maurício, A.S.R, Gustavo, B. Quique, J.F. Cor, C.A. Bernardino, T.D.R. Cláudio, M.M. Wuelton, V.G.L. Marcus, Effect of High vs LowDoses of Chloroquine Diphosphate as Adjunctive Therapy for Patients Hospitalized With Severe Acute Respiratory Syndrome Coronavirus 2 (SARS-CoV-2) Infection A Randomized Clinical Trial. JAMA Network Open. 2020;3(4):e208857. doi:10.1001/jamanetworkopen.2020.8857

[12]. C. Jun, L. Danping, L. Li, L. Ping, X. Qingnian, X. Lu, Y. Liu, H. Dan, S. Shuli, Z. Dandan, A. Zhiping, T. Li, S. Yinzhong, L. Hongzhou, A pilot study of hydroxychloroquine in treatment of patients with common coronavirus disease-19(COVID-19). Journal of Zhejiang University 2020;5(11):01-06. doi: doi:10.3785/j.issn.1008-9292.2020.03.03

[13]. C. Bin. W. Yeming. W. Danning,. W. Liu, W. Jingli,. F. Guohui,. R. Lianguo. S. Bin. C. Yanping. A Trial of Lopinavir-Ritonavir in Adults Hospitalized with Severe Covid-19. N Engl J Med. 2020;11(3):01-13. doi: 10.1056/NEJMoa2001282

[14]. C. Zhawei. H. Jijia, Z. Zongwei, J. Shan, H. Shoumeng, Y. Dandan, Z. Ruhong, H. Ben, Z. Zhang, Efficacy of hydroxychloroquine in patients with COVID-19: results of a randomized clinical trial. Cold Spring Harbor Laboratory. 2020;11(5):01-11. doi: https://doi.org/10.1101/2020.03.22.20040758

[15]. Q. Yang, Q. Sun, B. Jiang, H. Xu, M. Luo, P. Xie, W. Huang, Z. Cong, Retrospective clinical study on treatment of COVID-19 patients with integrated traditional Chinese and western medicine.Tianjin Institute of Pharmaceutical Research and Chinese Pharmaceutical Association. 2020; 11(5): 2050-2054. Trans. China. http://doi: 10.7501/j.issn.02532670.2020.08.009

[16]. R.W. Lu. W. Wang, X. Li, Clinical observation of 63 suspected cases of new coronavirus pneumonia treated with Chinese medicine Lianhua Qingwen. Journal of Traditional Chinese Medicine 2020;11(05):01-05. Trans.China.http://kns.cnki.net/kcms/detail/11.2166.R .20200215.1633.004.html 
[17]. K. Li. W. An. F. Xia, Min C. P. Yang, Y. Liao. X. Xu. Q. Zhou. S. Fang, M. Zhang, Observation on clinical effect of modified Qingfei Paidu Decoction in treatment of COVID-19. Tianjin Pharmaceutical Research Institute Chinese Pharmaceutical Association. 2020;:2046-20490. Trans. China. http:// DOI: $10.7501 /$ j.issn.0253-2670.2020.08.008

[18]. H. Sun, X. Feng, L. Zhang, C. Wei. J. Chen, Q. Wang, Zhen-hua J. Study on Clinical Efficacy of Lianhua Qingke Granule in Treatment of Mild and Ordinary COVID-19. Chinese Journal of Experimental Traditional Medical Formulae. 2020. Mai 11, 2020:01-09. Trans. China. http://kns.cnki.net/kcms/detail/detail.aspx?doi=10.134 22/j.cnki.syfjx.20201438

[19]. W. Xia, C. An, Zheng C. Zheng, Jixian Z. M. Huang, H. Y. Wang, W. Yang Fengwen Y. Can D. Zhengliang L. Qingquan L. Boli Z. Clinical study in 34 cases of new coronavirus pneumonia treated by traditional Chinese and Western integrated medicine. Journal of Traditional Chinese Medicine Trans. China. 2020 61, 5. 11(5):375-382. DOI: 10.13288 /j. 11 - $2166 \quad$ /r. $2020 . \quad 05 . \quad 002$. http://www.cnki.com.cn/Article/CJFDTotalZZYZ202005003.htm

[20]. C. Zhang, S. Zhang, W. Wang, X. Jiang, Clinical observation of Xuebijing in the treatment of COVID19. Chinese Journal of Hospital Pharmacy. Trans. China. 2020;11(5):0205. http://kns.cnki.net/kcms/detail/42.1204.r.2020040 9.1637.002.html

[21]. G. Navid, R.C. L.C. Ricahrd,H. Fingerhut, M.S. Jalali, A. Ebrahimvandi, A, Quaadgras, Model-Based Policy Analysis to Mitigate Post-Traumatic Stress Disorder. In: Gil-Garcia JR, Pardo TA, Luna-Reyes LF, editors. Policy Analytics, Modelling, and Informatics: Innovative Tools for Solving Complex Social Problems. Cham: Springer International Publishing. 2016 Jun. 387-406. http://hdl.handle.net/1721.1/102662

[22]. G. Navid, E. Alireza, S.J. Mohammad, A Dynamic Model of Post-Traumatic Stress Disorder for Military Personnel and Veterans. PLoS One. 2016;11(10):e0161405. doi: http://doi.org/10.1371/journal.pone.0161405

[23]. C.C. Anne, Goh, P.G. Hui, K. David, Treatment of COVID-19: old tricks for new challenges Critical Care; $\quad$ (2020) 24:91. https://doi.org/10.1186/s13054-020-2818-6

[24]. L. Hui, Q. Tang, S. Ya, L. Shi-bing, Y. Ming, R. Nicola, L. Jian-ping. Can Chinese Medicine Be Used for Prevention of Corona Virus Disease 2019 (COVID-19)? A Review of Historical Classics, Research Evidence and Current Prevention Programs. Chin J Integr Med. 2020 Apr;26(4):243-250. doi: $10.1007 / \mathrm{s} 11655-020-3192-6$
[25]. X. Shen, F. Fan, Treatment of novel coronavirus pneumonia from "warm-heat, dryness and toxin". Clinical Journal of Traditional Chinese Medicine (2020) 01:14. Trasn. China. http://kns.cnki.net/kcms/detail/34.1268.R.20200515.0 904.004.html

[26]. X. Guo, R. Sun, Decocção de Huanglian Jiedu no tratamento de novas pneumonias por coronavírus (COVID-19) Síndrome da síndrome de Qiying grave de duas queimaduras e relação do progresso da pesquisa farmacológica. Fitoterapia chinesa. 2020, $11 \mathrm{pp}$. 3070-3077. https://kns8.cnki.net/kcms/detail/detail.aspx?dbcode= cjfd \&dbname $=$ cjfdauto $\&$ filename $=$ zcyo202011027 \&u id=weevrecwsljhsldtteyzvtfpv2k0vky0de1bnhzmq0lb d1o2etliakx0md0 $=\$ 9 \mathrm{a} 4 \mathrm{hf} \_$yauvq5obgvaqnkpcycejken sw4iqmovwhtwkf4vypohbkxjw!!\&v=mtazodlose5ybz liwtrsogvymux1efltn0romvqzcvryv00xrnjdvvi3cwzzz wrwrkn2bfzil09qetdtwwjhneg=

[27]. Yanzhi L. Longjing W. Longfei. Yunbin J. Jie Y. Hojun. Shuting Z. Guanghua L. Zhiqun L. Pathogeny and pathogenesis research of coronavirus disease 2019 from perspective of "pathogenic dampness" based on network pharmacology. Chinese Traditional and Herbal Drugs. Vol. 51 N. 8 April 2020, pp. 20042014. Trans. China. http://www.tiprpress.com/zcy/article/abstract/2020080 4 DOI: 10.7501/j.issn.0253-2670.2020.08.004

[28]. Y. Qin, Q. Zhao, Y. Zhao, X. Ren, K. Bao, X. Li, C. Jiang, Exploring mechanism of Curcuma wenyujin against COVID-19. Chinese Traditional and Herbal Drugs. 2020; 51 (8):1977-1983. Trans. China. http://www.tiprpress.com/zcy/article/abstract/2020080 1 DOI: 10.7501/j.issn.0253-2670.2020.08.001

[29]. H. William, Y. Gao, R. Dianah, Chinese medicine and complex systems dynamics. Handbook of the Philosophy of Science. 2011; 10:674-719. http://dx.doi.org/10.1016/B978-0-444-52076-0.500237 